DOI: $10.5455 / 2320-1770 . \mathrm{ijrcog} 20130955$

Case Report

\title{
A rare case of Swyer's syndrome
}

\section{Vijaya M. Babre*, Kirti Bendre, Geeta Niyogi}

Department of Obstetrics \& Gynaecology, K.J. Somaiya Medical College and Research Centre, Sion 400022, Mumbai, Maharashtra, India

Received: 23 July 2013

Accepted: 4 August 2013

\section{*Correspondence:}

Dr. Vijaya M. Babre,

E-mail: drvbabre@gmail.com

(C) 2013 Babre VM et al. This is an open-access article distributed under the terms of the Creative Commons Attribution Non-Commercial License, which permits unrestricted non-commercial use, distribution, and reproduction in any medium, provided the original work is properly cited.

\begin{abstract}
Swyer syndrome was first described by Jim Swyer in 1955. It is a form of "Pure Gonadal Dysgenesis". The affected female has 46XY karyotype. A 17 year old unmarried girl came with complaints of primary amenorrhea, non development of breast. On examination she has normal built. Examination of secondary sexual characters revealed no breast development, pubic and axillary hairs were sparse. Female type of genitalia with vaginal opening. Serum FSH was $117.5 \mathrm{mIU} / \mathrm{ml}$. Thyroid and Prolactin was in normal range. Karyotype showed genotype of 46XY. Diagnostic laparoscopy showed streak gonads, small uterus, and normal fallopian tubes. Diagnosis of Swyer syndrome was made. Patient was started on hormonal replacement therapy (HRT). In Swyer syndrome there is a mutation of SRY gene leads failure of development of testis. Mullerian duct development takes place by default. These patients can have normal sexual intercourse and can become pregnant by donor oocyte. They need to be on HRT. The risk of gonadoblastoma and dysgerminoma are very high in streak gonads so bilateral gonadectomy is advised.
\end{abstract}

Keywords: Swyer's syndrome, Primary amenorrhea

\section{INTRODUCTION}

Swyer's syndrome was first described by Jim Swyer in 1955. Affected individuals have an XY karyotype but external and internal genitalia are of the female type. The gonads are usually replaced by fibrous streaks. Patients usually present in adolescence with primary amenorrhea and lack of secondary sexual characters. Swyer's syndrome is a rare entity incidence being 1:30,000.

Purpose of reporting this case is its rarity and importance of diagnosis of XY female as there is high incidence of gonad malignancy, in affected person.

\section{CASE REPORT}

A 17 year old girl came to OPD with her mother with complaints of primary amenorrhea and no development of breast.
There was no history of cyclical abdominal pain, hormonal intake, radiation exposure, chemotherapy or any central nervous symptoms such as headache or visual disturbances. There was no past significant surgical history. There was neither history of childhood tuberculosis nor history of Koch's in the family.

She was the first child of a non-consanguineous marriage. She has one younger sister of 15 yrs old who has got her menarche at age of 14 yrs.

On general examination she was $143 \mathrm{~cm}$. tall and weighs $39 \mathrm{~kg}$. Body mass index was (BMI) $18 \mathrm{~kg} / \mathrm{m}^{2}$.There was no evidence of acanthosis nigricans, acne, hirsutism, goiter, cushingoid features of Turner's stigmata, like webbed neck, cubitus valgus. Examination of secondary sexual characteristics revealed no breast development with hypopigmented areola. Public and axillary hair were sparse. 
Examination of external genitalia revealed that they were of female type and there was no evidence of clitoromegaly. Vaginal opening was seen. After investigation, serum follicle stimulating hormone (FSH) was found to be very high $-117.5 \mathrm{mIU} / \mathrm{ml}$.

Serum TSH and serum prolactin were normal. Ultrasound showed a rudimentary uterus and bilaterally ill-defined adnexa, no renal abnormality was detected.

A karyotype was done which showed a genotype of 46XY (Figure 1).

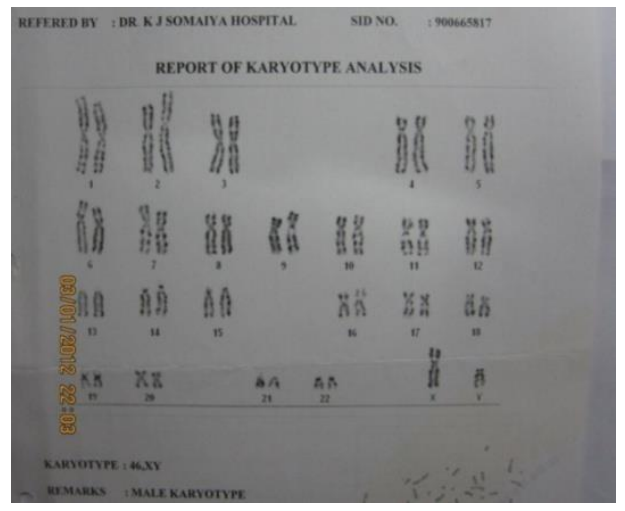

Figure 1: Karyotype report showing a genotype of 46XY.

Patient was subjected for a diagnostic laparoscopy which showed a small uterus and bilateral normal fallopian tubes. Ovaries could not be visualized; fibrous bands were seen on either side. No any other pelvic abnormality seen.

In view of streak gonads and genotype of XY diagnosis of Swyer syndrome was made.

Counseling of parents done. Patient was started on hormone replacement therapy (HRT) with conjugated estrogen $1.25 \mathrm{mg}$ per day and cyclical medroxy progesterone acetate.

Three months after initiation of HRT patients attained menarche with one episode of spotting per vaginum. The secondary sexual characteristics have shown improvement. Breast development occurred Tanner stage II.

\section{DISCUSSION}

Swyer syndrome is a form of pure gonadal dysgenesis. ${ }^{1}$

The first known step of sexual differentiation of a normal $\mathrm{XY}$ fetus is the development of testes. The early stages of testicular formation in the second month of gestation requires the action of several genes, most important is SRY, the sex determining region of the Y chromosome. ${ }^{4}$

Mutations of SRY accounts for many cases of Swyer syndrome. When such a gene is defective the indifferent gonads fail to differentiate into testes in an XY (genetically male) fetus. Without testes, no testosterone or antimullerian hormone (AMH) is produced. Without testosterone the external genitalia fail to virilize, ${ }^{2}$ resulting in normal female genitalia. Without $\mathrm{AMH}$ the mullerian duct develops into normal internal female organs i.e. uterus, fallopian tubes, cervix and vagina. ${ }^{1}$

A baby who is born externally and is normal in all anatomic aspects except that the child has nonfunctional streak gonads. Because of the inability of the streak gonads to produce sex hormones (both estrogens and androgens) most of the secondary sex characters do not develop. Therefore, there is absence of breast development, widening of the pelvis and hips and menstrual periods. Adrenal gland is not affected and can produce androgens and most of these persons will develop pubic hair, though it often remains sparse.

We made a diagnosis of Swyer's syndrome because patient was a normal statured girl with primary amenorrhea with clinical features of sexual infantilism whose genotype was pure $\mathrm{XY}$ and the gonadal tissues are fibrous band (Figure 2).

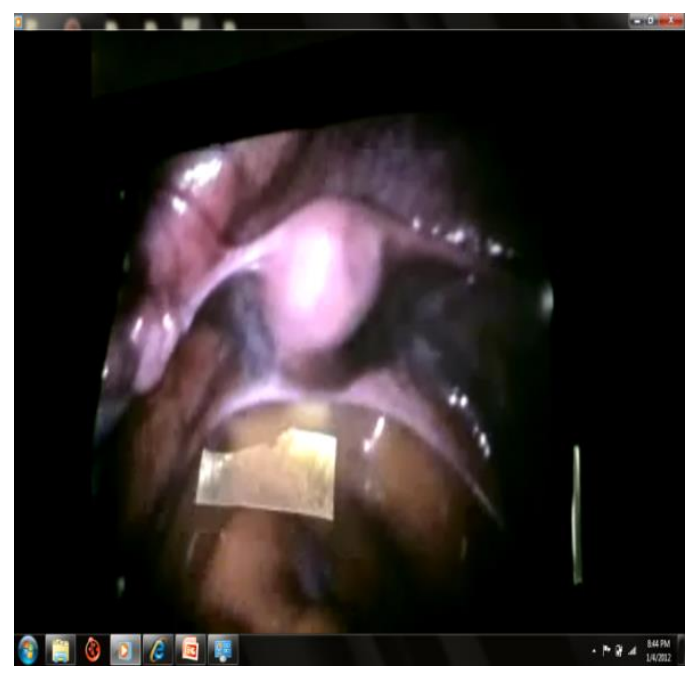

Figure 2: Laparoscopic view of streak gonads.

The main differential diagnosis of sawyer's syndrome is mixed gonadal dysgenesis which is more frequently seen than the former. In this condition the gonads on histopathology will also show testicular differentiation in addition to ovarian differentiation. ${ }^{5}$ The genotype too is usually a mosaic pattern. The incidence of malignant gonadoblastoma in patients with dysgenetic gonads is high $25-35 \%$ and gonadectomy done for this patient. ${ }^{3,6}$

These patients can have a normal sexual intercourse and they need HRT for development of breast and to prevent osteoporosis.

They can conceive using donor oocytes and artificial reproductive techniques. 


\section{CONCLUSION}

Swyer syndrome is extremely rare case of primary amenorrhea. Genetic testing plays very crucial role in diagnosis of Swyer syndrome. In patients of $\mathrm{Y}$ chromosome there is high incidence of gonadoblastoma and dysgerminoma so gonadectomy is must.

\section{Funding: None}

Conflict of interest: Not declared

Ethical Approval: Not required

\section{REFERENCES}

1. Jonathan S. Berek, Novak's Gynaecology, Chapter 23 Puberty $13^{\text {th }}$ ed. Philadelphia: Williams \& Wilkins 2002; pg 821.

2. Hersmus R, Stoop H. A novel SRY missense mutation affecting nuclear import in a $46, \mathrm{XY}$ female patient with bilateral gonadoblastoma. Eur J Hum Genet. 2009 December;17(12):1642-9.

3. Michala L, Goswami D, Creighton SM, Conway GS. Swyer syndrome: presentation and outcomes. BJOG. 2008 May;115(6):737-41.

4. Clinical Gyanecology Endocrinology and infertility Leon Speroff and Marc A. Fritz, $17^{\text {th }}$ edition, Chapter 9, Normal \& Abnormal sexual development, pg 345359.

5. Baltimore: Lippincott Williams and Wilkins 1999: pg 367-368.

6. Williams Gynaecology 2008 edited by John O Schorge (et al), $1^{\text {st }}$ edition, chapter 18 , Anatomic Disorders, pg 410.

DOI: 10.5455/2320-1770.ijrcog20130955

Cite this article as: Babre VM, Bendre K, Niyogi G. A rare case of Swyer's syndrome. Int J Reprod Contracept Obstet Gynecol 2013;2:485-7. 